\title{
Bioequivalence and Population Pharmacokinetic Modeling of Two Forms of Antibiotic, Cefuroxime Lysine and Cefuroxime Sodium, after Intravenous Infusion in Beagle Dogs
}

\author{
Longshan Zhao, ${ }^{1}$ Qing Li, ${ }^{1}$ Xingang Li, ${ }^{2}$ Ran Yin, ${ }^{1}$ Xiaohui Chen, ${ }^{1}$ \\ Lulu Geng, ${ }^{1}$ and Kaishun $\mathrm{Bi}^{1}$ \\ ${ }^{1}$ School of Pharmacy, Shenyang Pharmaceutical University, Shenyang 110016, China \\ ${ }^{2}$ Department of Pharmacy, Beijing Tiantan Hospital Affiliated to Capital Medical University, Beijing 100050, China
}

Correspondence should be addressed to Kaishun Bi, bikaishun@yahoo.com

Received 22 January 2012; Accepted 14 May 2012

Academic Editor: Andre Van Wijnen

Copyright ( $\odot 2012$ Longshan Zhao et al. This is an open access article distributed under the Creative Commons Attribution License, which permits unrestricted use, distribution, and reproduction in any medium, provided the original work is properly cited.

\begin{abstract}
To investigate the bioequivalence and the population pharmacokinetics of cefuroxime lysine and cefuroxime sodium in healthy beagle dogs. A randomized 2-period crossover design in 18 healthy beagle dogs after receiving 20, 40, and $80 \mathrm{mg} / \mathrm{kg}$ of cefuroxime lysine or cefuroxime sodium was conducted. A 3-compartment open model was used as the basic model for the population pharmacokinetic study. Both of the antibiotics exhibited dose-proportional pharmacokinetics over the dose range of $20-80 \mathrm{mg} / \mathrm{kg}$. The mean relative bioavailability of cefuroxime lysine versus cefuroxime sodium was 1.05 (range, 0.71 to 1.42 ), with a significant difference between males and females. The estimates of population pharmacokinetic of CL, $V_{1}, Q_{2}, V_{2}, Q_{3}, V_{3}$ were $3.74 \mathrm{~mL} / \mathrm{h}$, $1.70 \mathrm{~mL}, 29.5 \mathrm{~mL} / \mathrm{min}, 3.58 \mathrm{~mL}, 0.31 \mathrm{~mL} / \mathrm{min}$, and $158 \mathrm{~mL}$ for cefuroxime lysine and $4.10 \mathrm{~mL} / \mathrm{h}, 1.00 \mathrm{~mL}, 38.5 \mathrm{~mL} / \mathrm{min}, 4.19 \mathrm{~mL}$, $0.06 \mathrm{~mL} / \mathrm{min}$, and $13.6 \mathrm{~mL}$ for cefuroxime sodium, respectively. The inter-individual variability was determined to be less than 29.1\%. A linear pharmacokinetic was revealed for cefuroxime lysine and cefuroxime sodium in dogs after intravenous infusion, and the bioequivalence of these forms of the antibiotic was observed with the significant gender-related differences in mean relative bioavailability of cefuroxime lysine versus cefuroxime sodium.
\end{abstract}

\section{Introduction}

Cefuroxime sodium is a semisynthetic, broad-spectrum, and considered as a second-generation cephalosporins antibiotic agent for parenteral administration. This antibiotic has been widely used for the treatments for patients having infections of soft tissue, respiratory tract, urinary tract, genital tract, central nervous system, and bone and joint tissues [1-4]. Another new cefuroxime salt, namely, cefuroxime lysine, having the merits of higher water solubility and less irritation to the veins, has also been proposed for clinical application.

In general, cefuroxime sodium, formulated as a lyophilised crystalline powder, is administered by intravenous, intramuscular, or intraperitoneal injection routes. The pharmacokinetic properties of cefuroxime sodium have been determined in several species, including goats, calves, rats, and humans [5-9]. In most cases, a 2-compartment open model was considered to be the best model fitting the administration of cefuroxime sodium and which showed the values of $t_{1 / 2}$ to be $1.48 \mathrm{~h}$ after the intravenous or intramuscular injection of the antibiotic. Another salt of cefuroxime is cefuroxime lysine, which is a possible alternative of cefuroxime sodium. However, the pharmacokinetic studies on cefuroxime lysine are very limited. The information of cefuroxime lysine regarding its absorption, distribution, metabolism, and excretion is missing. In order to facilitate the research and development of cefuroxime lysine, the current study aimed to determine the pharmacokinetic properties of a 30 min intravenous infusion of cefuroxime lysine, or cefuroxime sodium (serving as a control), in healthy young beagle dogs. The differences in pharmacokinetic parameters between the two chemical forms of the antibiotic 
were compared. Moreover, we also aimed to explore the pharmacokinetic linearity for both antibiotics, as well as to monitoring the possible tolerability and side effects. Lastly, a population pharmacokinetic model was developed and evaluated.

\section{Materials and Methods}

2.1. Animals. Eighteen healthy beagle dogs (gender in half, $10.40-14.25 \mathrm{~kg}$, aged 9-14 months) were obtained from the Experimental Animal Research and Development Center of Guangzhou Institute of Pharmaceutical Industry (Guangzhou, China), and they were housed individually in the stainless-steel cages in a controlled environment. Filtered tap water and a standard animal diet were available ad libitum. Six animals were enrolled in each group. Before the experiment, the dogs were confirmed to be clinically healthy according to a prestudy of a physical and haematological examination. The dogs had no previous exposure to any antibiotic and other drugs during the acclimation or the study periods. The animal study was carried out in accordance with the Guidelines for Animal Experiment of Shenyang Pharmaceutical University (Shenyang, China), and the protocol was approved by Animal Ethics Committee of the Institute.

2.2. Experimental Design. The study design was a randomized 2-period crossover using a double-blind, parallel-group, ascending-single-dose, and a week washout period between the treatments. Three dosages (containing 20, 40,80 mg/kg according to cefuroxime) of cefuroxime sodium (purity: 98.0\%, GlaxoSmithKline Manufacturing S.p.A., Italy) and cefuroxime lysine (purity: 98.8\%, Shandong Luoxin Pharmacy Stock Co., Ltd., Shandong, China) were dissolved in $0.9 \% \mathrm{NaCl}$ sterile solution. The drugs were infused constantly for $30 \mathrm{~min}$ with an infusion pump via the hindlimb vein of the dogs. The dose was selected based on the amount normally administered to human in clinic. The blood samples $(1 \mathrm{~mL})$ were withdrawn via the foreleg vein into $1.5 \mathrm{~mL}$ heparinized tubes at -0.5 (to serve as a control), $-0.42,-0.33,-0.25,0$ (the end of infusion) and $0.25,0.5$, $1,1.5,2,4,6,8,10,12 \mathrm{~h}$ after the end of the infusion. The plasma samples were immediately centrifuged at $3500 \mathrm{~g}$ for $10 \mathrm{~min}$ and stored at $-80^{\circ} \mathrm{C}$ until analysis.

2.3. Analysis of Blood Samples. A triple-quadrupole tandem mass spectrometer (Micromass Quattro micro API mass spectrometer, Waters Corp., Milford, MA, USA) equipped with electrospray ionization (ESI) interface was used for analytical detection [10]. In brief, an ACQUITY bridged ethyl hybrid $(\mathrm{BEH}) \mathrm{C}_{18}$ column $(50 \mathrm{~mm} \times 2.1 \mathrm{~mm}, 1.7 \mu \mathrm{m}$; Waters Corp.), an internal standard (IS) of phenacetin, and a mobile phase consisting of acetonitrile- $0.1 \%$ formic acid in $10 \mathrm{mM}$ ammonium acetate $(40: 60, v / v)$ were used. The ESI source was operated in positive ionization mode. Quantification was performed using multiple reaction monitoring (MRM) of the transitions of $m / z 442.1 \rightarrow 363.8$ for cefuroxime and $\mathrm{m} / \mathrm{z} 180.1 \rightarrow 109.8$ for IS, with the scan time of $0.20 \mathrm{~s}$ per transition. The optimal MS parameters were as follows: capillary voltage $2.8 \mathrm{kV}$, cone voltage $14 \mathrm{~V}$ for cefuroxime and $20 \mathrm{~V}$ for IS, source temperature $110^{\circ} \mathrm{C}$, and desolvation temperature $450^{\circ} \mathrm{C}$. Nitrogen was used as the desolvation and cone gas with a flow rate of 500 and $30 \mathrm{~L} / \mathrm{h}$. Argon was used as the collision gas at a pressure of approximately $0.213 \mathrm{~Pa}$. The optimized collision energy for cefuroxime and IS was 8 and $20 \mathrm{eV}$, respectively. All data were collected in centroid mode and processed using MassLynx NT 4.1 software with QuanLynx program (Waters Corp.). Ten $\mu$ l of sample was injected onto an UPLC-MS/MS system with the lower limit of quantification of $0.01 \mu \mathrm{g} / \mathrm{mL}$. The intra- and interday precisions in all samples were less than $8.1 \%$, while the accuracy was within $\pm 6.2 \%$ of the nominal values.

2.4. Pharmacokinetic Analysis. Pharmacokinetic parameters of cefuroxime lysine and cefuroxime sodium were calculated from plasma concentration-time curves using WinNonlin 5.2 (Pharsight Corporation, Mountain View, CA, USA) and DRUG AND STATISTICS software (DAS, version 2.1.1, Mathematical Pharmacology Professional Committee of China) by noncompartmental and compartmental modeling approaches. All values were averaged across different individuals and their standard errors were calculated.

2.4.1. Noncompartmental Pharmacokinetic Analysis. For each subject, the maximum plasma concentration $\left(C_{\max }\right)$ and its corresponding time $\left(T_{\max }\right)$ of the antibiotics were determined by visual inspection of the profiles. The apparent terminal elimination rate constant $(\lambda)$ was calculated by linear regression of the natural logarithms of the terminal plasma concentrations. The terminal half life $\left(t_{1 / 2}\right)$ was derived from $0.693 / \lambda$. The area under the curve to the last measured point $\left(\mathrm{AUC}_{0-t}\right)$ was calculated using the trapezoidal rule. The area under the plasma concentration versus time curve from $0 \mathrm{~h}$ to infinite time $\left(\mathrm{AUC}_{0-\infty}\right)$ was calculated as the sum of $\mathrm{AUC}_{0-t}$ and $C_{t} / \lambda$, while $C_{t}$ was the last quantifiable concentration. Total body systemic clearance (CL) was determined as the given dose divided by the AUC, and this value was normalized to the body weight. The total body weight-normalized apparent volume of distribution $(V)$ was calculated as $\mathrm{CL} / \lambda / W$, where $W$ was the body weight of the subject. The mean residence time (MRT) was calculated by $\mathrm{MRT}=\mathrm{AUMC}_{0-\infty} / \mathrm{AUC}_{0-\infty}$.

2.4.2. Compartmental Pharmacokinetic Analysis. In order to select the basic model for the population pharmacokinetic analysis, WinNonlin and DAS programs were used here to perform classic compartmental pharmacokinetic analysis. One-, two-, and three-compartment open model were employed to describe the observed data, respectively, and the best one was selected as the basic model of population pharmacokinetics.

2.4.3. Population Pharmacokinetic Modeling. A total of 504 plasma samples were used to establish the population pharmacokinetic model using the nonlinear mixed effects modeling (NONMEM) program (version 7.1, GloboMax 
TABle 1: Demographic of the drug administrated for 18 beagle dogs.

\begin{tabular}{lcccr}
\hline Antibiotics $(\mathrm{mg} / \mathrm{kg})^{\mathrm{a}}$ & Sex $^{\mathrm{b}}$ & Age $(\mathrm{m})^{\mathrm{c}}$ & \multicolumn{2}{c}{${\text { Weight }(\mathrm{kg})^{\mathrm{c}}}^{2}$ week } \\
\hline \multirow{2}{*}{20} & M & $11.3 \pm 0.58$ & $13.6 \pm 0.40$ & $14.7 \pm 0.25$ \\
& F & $11.0 \pm 0$ & $12.9 \pm 1.18$ & $13.2 \pm 1.22$ \\
40 & M & $10.3 \pm 1.15$ & $13.0 \pm 1.52$ & $14.0 \pm 1.67$ \\
& F & $12.0 \pm 1.73$ & $13.0 \pm 2.08$ & $13.6 \pm 1.77$ \\
& M & $12.3 \pm 2.89$ & $11.7 \pm 0.35$ & $12.7 \pm 0.71$ \\
& F & $11.0 \pm 2.65$ & $10.9 \pm 0.64$ & $11.4 \pm 0.72$ \\
\hline
\end{tabular}

a : The administrated antibiotics (both cefuroxime forms).

b: M: male, F: female.

c: Data are listed as means $\pm \mathrm{SD}$, where $n=3$.

TABLE 2: Noncompartmental pharmacokinetic parameters obtained for cefuroxime lysine and cefuroxime sodium by using the WinNonlin analysis.

\begin{tabular}{|c|c|c|c|c|c|c|}
\hline \multirow{2}{*}{ Parameter } & \multicolumn{3}{|c|}{ Cefuroxime sodium } & \multicolumn{3}{|c|}{ Cefuroxime lysine } \\
\hline & $20(\mathrm{mg} / \mathrm{kg})$ & $40(\mathrm{mg} / \mathrm{kg})$ & $80(\mathrm{mg} / \mathrm{kg})$ & $20(\mathrm{mg} / \mathrm{kg})$ & $40(\mathrm{mg} / \mathrm{kg})$ & $80(\mathrm{mg} / \mathrm{kg})$ \\
\hline$\lambda$ & $0.52 \pm 0.18$ & $0.63 \pm 0.18$ & $0.51 \pm 0.26$ & $0.53 \pm 0.19$ & $0.77 \pm 0.08$ & $0.57 \pm 0.29$ \\
\hline$t_{1 / 2}(\mathrm{~h})$ & $1.50 \pm 0.63$ & $1.21 \pm 0.43$ & $1.29 \pm 0.39$ & $1.46 \pm 0.57$ & $0.91 \pm 0.11$ & $1.09 \pm 0.35$ \\
\hline$V(\mathrm{~L} / \mathrm{kg})$ & $0.66 \pm 0.24$ & $0.62 \pm 0.33$ & $0.60 \pm 0.18$ & $0.65 \pm 0.28$ & $0.41 \pm 0.07$ & $0.48 \pm 0.13$ \\
\hline $\mathrm{CL}(\mathrm{L} / \mathrm{h} / \mathrm{kg})$ & $0.31 \pm 0.05$ & $0.34 \pm 0.06$ & $0.32 \pm 0.04$ & $0.31 \pm 0.03$ & $0.31 \pm 0.04$ & $0.32 \pm 0.07$ \\
\hline $\mathrm{MRT}_{0-\infty}(\mathrm{h})$ & $1.86 \pm 0.78$ & $1.54 \pm 0.21$ & $1.32 \pm 0.12$ & $1.85 \pm 0.48$ & $1.39 \pm 0.12$ & $1.43 \pm 0.22$ \\
\hline$T_{\max }$ & $0.63 \pm 0.44$ & $0.54 \pm 0.10$ & $0.46 \pm 0.10$ & $0.79 \pm 0.60$ & $0.50 \pm 0.00$ & $0.54 \pm 0.10$ \\
\hline$C_{\max }(\mathrm{mg} / \mathrm{L})$ & $41.05 \pm 12.28$ & $84.20 \pm 19.15$ & $186.9 \pm 29.6$ & $40.37 \pm 15.8$ & $92.46 \pm 19.3$ & $175.7 \pm 48.7$ \\
\hline $\mathrm{AUC}_{0-\infty}(\mathrm{mg} \cdot \mathrm{h} / \mathrm{L})$ & $65.41 \pm 11.7$ & $121.5 \pm 23.8$ & $256.5 \pm 33.6$ & $66.04 \pm 6.45$ & $130.9 \pm 18.3$ & $259.3 \pm 56.6$ \\
\hline $\mathrm{AUMC}_{0-\infty}$ & $126.2 \pm 77.1$ & $187.2 \pm 41.2$ & $341.9 \pm 71.1$ & $123.3 \pm 36.1$ & $181.1 \pm 23.3$ & $371.9 \pm 98.6$ \\
\hline$C_{\text {adjusted }}$ & $2.05 \pm 0.61$ & $2.10 \pm 0.48$ & $2.34 \pm 0.37$ & $2.02 \pm 0.79$ & $2.31 \pm 0.48$ & $2.20 \pm 0.61$ \\
\hline AUC $_{\text {adjusted }}$ & $3.27 \pm 0.58$ & $3.04 \pm 0.59$ & $3.21 \pm 0.42$ & $3.30 \pm 0.18$ & $3.27 \pm 0.46$ & $3.24 \pm 0.71$ \\
\hline
\end{tabular}

The denotations are $\lambda$ : elimination rate constant; $t_{1 / 2}$ : the drug elimination half-life; $V$ : volume of distribution; CL: clearance; $\mathrm{MRT}_{0-\infty}: \mathrm{mean}_{\text {residence }}$ time from time zero to infinity; $T_{\max }$ : time to reach peak concentration; $C_{\max }$ : peak concentration, $\mathrm{AUC}_{0-\infty}$ : the area under the plasma concentration-time curve from time zero to infinity; $\mathrm{AUMC}_{0-\infty}$ : area under the first moment curve from time zero to infinity; $C_{\text {adjusted }} C_{\max }$ adjusted by dose; $\mathrm{AUC}_{\text {adjusted: }}$ $\mathrm{AUC}_{0-\infty}$ adjusted by dose; the values are expressed by mean $\pm \mathrm{SD}$, where $n=6$.

TABLE 3: Noncompartmental pharmacokinetic parameters obtained for cefuroxime lysine and cefuroxime sodium by using DAS analysis.

\begin{tabular}{|c|c|c|c|c|c|c|}
\hline \multirow{2}{*}{ Parameter } & \multicolumn{3}{|c|}{ Cefuroxime sodium } & \multicolumn{3}{|c|}{ Cefuroxime lysine } \\
\hline & $20(\mathrm{mg} / \mathrm{kg})$ & $40(\mathrm{mg} / \mathrm{kg})$ & $80(\mathrm{mg} / \mathrm{kg})$ & $20(\mathrm{mg} / \mathrm{kg})$ & $40(\mathrm{mg} / \mathrm{kg})$ & $80(\mathrm{mg} / \mathrm{kg})$ \\
\hline$\lambda$ & $0.56 \pm 0.09$ & $0.72 \pm 0.16$ & $0.50 \pm 0.30$ & $0.62 \pm 0.13$ & $0.80 \pm 0.17$ & $0.77 \pm 0.30$ \\
\hline$t_{1 / 2}(\mathrm{~h})$ & $1.27 \pm 0.21$ & $1.01 \pm 0.23$ & $1.48 \pm 0.86$ & $1.15 \pm 0.20$ & $0.90 \pm 0.21$ & $0.98 \pm 0.28$ \\
\hline$V(\mathrm{~L} / \mathrm{kg})$ & $0.58 \pm 0.14$ & $0.46 \pm 0.12$ & $0.63 \pm 0.31$ & $0.51 \pm 0.08$ & $0.41 \pm 0.11$ & $0.42 \pm 0.07$ \\
\hline CL (L/h/kg) & $0.31 \pm 0.05$ & $0.34 \pm 0.06$ & $0.32 \pm 0.04$ & $0.31 \pm 0.02$ & $0.31 \pm 0.04$ & $0.32 \pm 0.07$ \\
\hline MRT (h) & $1.83 \pm 0.79$ & $1.54 \pm 0.21$ & $1.32 \pm 0.11$ & $2.11 \pm 0.62$ & $1.38 \pm 0.13$ & $1.42 \pm 0.20$ \\
\hline$T_{\max }$ & $0.63 \pm 0.44$ & $0.54 \pm 0.10$ & $0.46 \pm 0.10$ & $0.79 \pm 0.60$ & $0.50 \pm 0.00$ & $0.54 \pm 0.10$ \\
\hline$C_{\max }(\mathrm{mg} / \mathrm{L})$ & $41.05 \pm 12.28$ & $84.20 \pm 19.15$ & $186.9 \pm 29.6$ & $40.37 \pm 15.8$ & $92.46 \pm 19.3$ & $175.7 \pm 48.7$ \\
\hline $\mathrm{AUC}_{0-\infty}(\mathrm{mg} \cdot \mathrm{h} / \mathrm{L})$ & $65.35 \pm 11.7$ & $121.6 \pm 23.5$ & $256.5 \pm 33.4$ & $65.63 \pm 3.61$ & $130.8 \pm 18.3$ & $259.2 \pm 56.6$ \\
\hline $\mathrm{AUMC}_{0-\infty}$ & $124.3 \pm 75.7$ & $187.8 \pm 39.2$ & $340.4 \pm 67.1$ & $138.4 \pm 40.1$ & $180.1 \pm 23.6$ & $369.7 \pm 98.6$ \\
\hline$C_{\text {adjusted }}$ & $2.05 \pm 0.61$ & $2.10 \pm 0.48$ & $2.34 \pm 0.37$ & $2.02 \pm 0.79$ & $2.31 \pm 0.48$ & $2.20 \pm 0.61$ \\
\hline $\mathrm{AUC}_{\text {adjusted }}$ & $3.27 \pm 0.58$ & $3.04 \pm 0.59$ & $3.21 \pm 0.42$ & $3.28 \pm 0.18$ & $3.27 \pm 0.46$ & $3.24 \pm 0.71$ \\
\hline
\end{tabular}

The denotations are $\lambda$ : elimination rate constant; $t_{1 / 2}$ : the drug elimination half life; $V$ : volume of distribution; CL: clearance; $\mathrm{MRT}_{0-\infty}: \mathrm{mean}_{\text {residence }}$ time from time zero to infinity; $T_{\max }$ : time to reach peak concentration; $C_{\max }$ : peak concentration; $\mathrm{AUC}_{0-\infty}$ : the area under the plasma concentration-time curve from time zero to infinity; $\mathrm{AUMC}_{0-\infty}$ : area under the first moment curve from time zero to infinity; $C_{\text {adjusted }} C_{\text {max }}$ adjusted by dose; $\mathrm{AUC}_{\text {adjusted: }}$ $\mathrm{AUC}_{0-\infty}$ adjusted by dose; the values are expressed by mean $\pm \mathrm{SD}$, where $n=6$. 

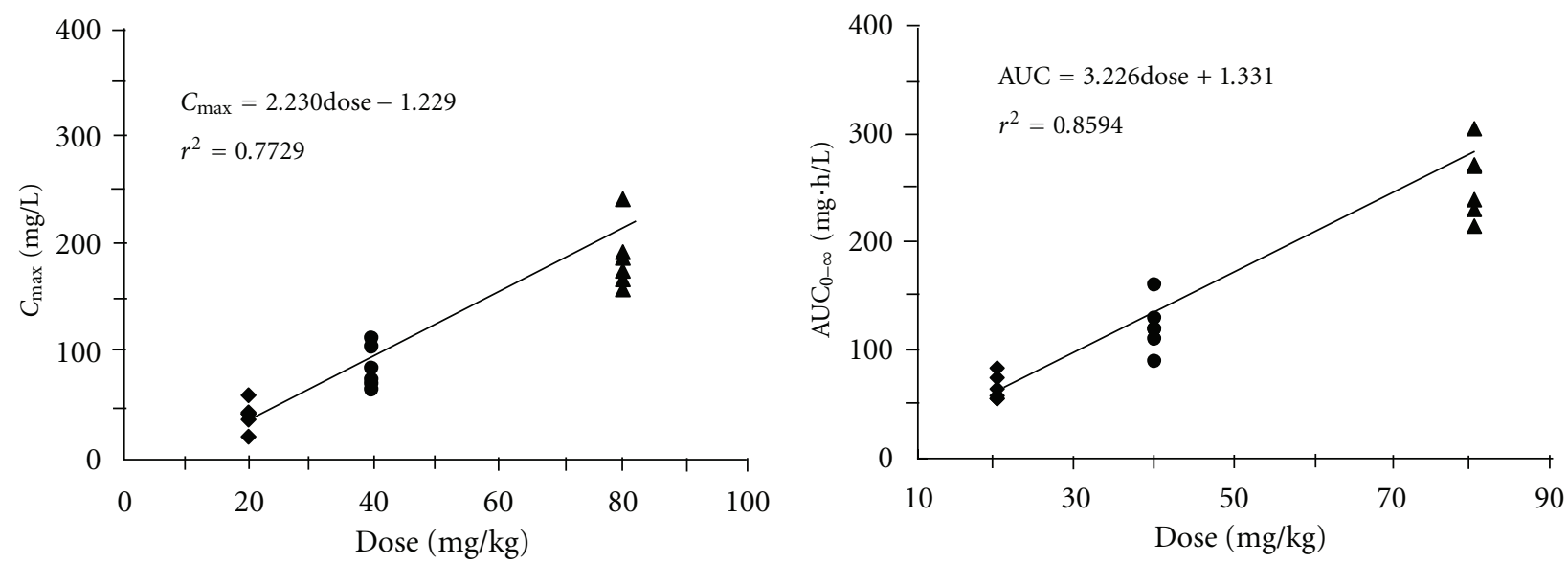

(a)
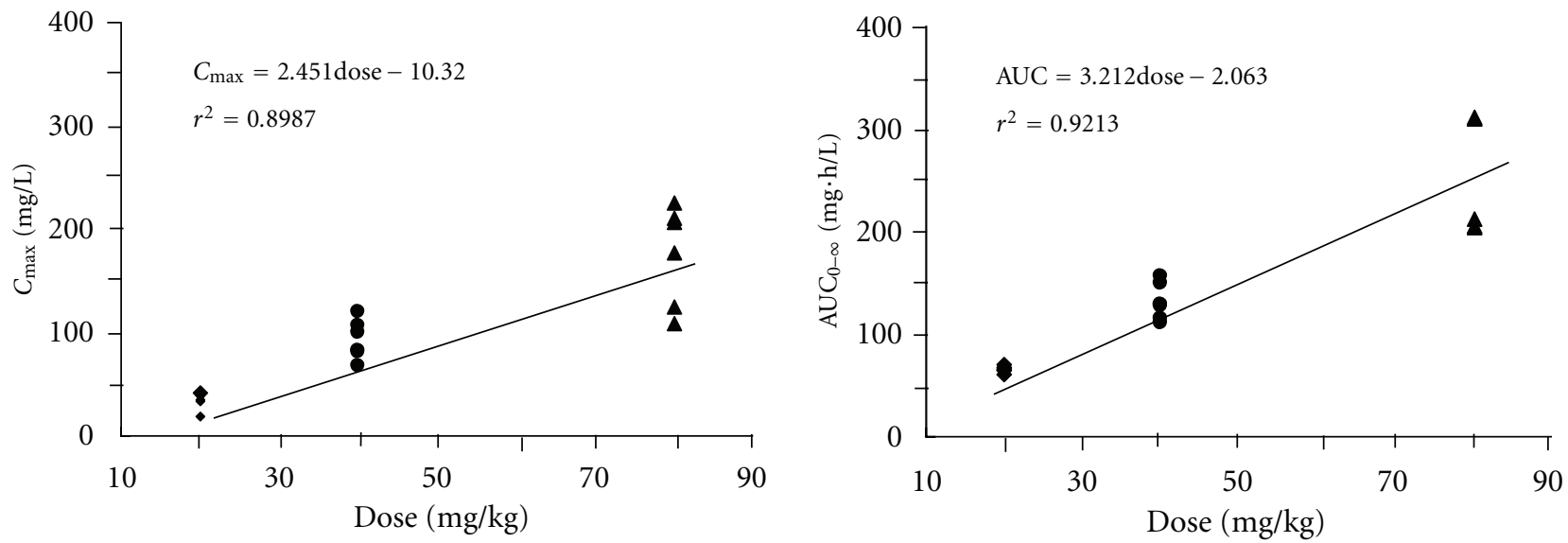

(b)

FIgURE 1: Plots of $C_{\max }$ and $\mathrm{AUC}_{0-\infty}$ of cefuroxime lysine (a) and cefuroxime sodium (b) versus different drug dosages in dogs. The indicated regression equations and its interrelation coefficients $\left(r^{2}\right)$ of $C_{\max }$ and AUC for cefuroxime lysine and cefuroxime sodium were calculated from the calibrated straight lines.

TABLE 4: The linear regression equation of cefuroxime lysine and cefuroxime sodium calculated by predicted/observed drug concentrations with a 3-compartment open model.

\begin{tabular}{llccc}
\hline $\begin{array}{l}\text { Dose } \\
\mathrm{mg} / \mathrm{kg}\end{array}$ & \multicolumn{2}{c}{ Cefuroxime sodium } & \multicolumn{2}{c}{ Cefuroxime lysine } \\
\hline 20 & Regression equation & $R^{2}$ & Regression equation & $R^{2}$ \\
40 & $y=0.9998 x+0.2175$ & 0.9885 & $y=0.9698 x+0.6396$ & 0.9697 \\
80 & $y=0.9709 x+1.303$ & 0.9775 & $y=1.002 x-0.1707$ & 0.9940 \\
\hline
\end{tabular}

LLC, Ellicott City, MD) with the fixed factors of dose, age, body weight, and gender as covariates $[11,12]$. All nonmem analyses were determined by the first-order conditional estimation. The model comparisons were made using the resulting decrease of objective function value (OFV) by nonmem. The critical $P$ value used throughout was 0.05 $(\mathrm{OFV}=3.84)$. The addition of one covariate could lead to the changes of the OFV: this change resembled a $\chi^{2}$ distribution with a 1 degree of freedom (df). Additional population models were examined with the progressive introduction of any covariates, which were found to contribute to the statistically significant drop in OFV. A recursive backward elimination procedure was then performed to further refine the model, and a covariate would be removed from the model if the increase in OFV was less than $10.84(P<0.001)$ during the exclusion [13].

2.5. Statistical Analysis. The statistical analyses were performed by using SPSS software (version 16.0; SPSS Inc., Chicago, IL). A one-way analysis of variance (ANOVA) was used to determine the difference in different formulations, dosages, and genders. Bioequivalence of cefuroxime 
TABle 5: Population pharmacokinetic parameter estimates of cefuroxime lysine and cefuroxime sodium in dog plasma after intravenous infusion in $30 \mathrm{~min}(20,40,80 \mathrm{mg} / \mathrm{kg})$ obtained by 3 -compartment pharmacokinetic model.

\begin{tabular}{|c|c|c|c|c|c|c|}
\hline \multirow{2}{*}{ Parameter } & \multicolumn{3}{|c|}{ Cefuroxime lysine } & \multicolumn{3}{|c|}{ Cefuroxime sodium } \\
\hline & Value & RSE (\%) & $\sigma$ & Value & RSE (\%) & $\sigma$ \\
\hline $\mathrm{Cl}(\mathrm{mL} / \mathrm{h})$ & 3.74 & 13.5 & 0.035 & 4.10 & 18.2 & 0.0173 \\
\hline$V_{1}(\mathrm{~mL})$ & 1.70 & 6.3 & 0.881 & 1.00 & 19.1 & 0.626 \\
\hline$Q_{2}(\mathrm{~mL} / \mathrm{min})$ & 29.5 & 3.5 & 1.77 & 38.5 & 25.7 & 0.47 \\
\hline$V_{2}(\mathrm{~mL})$ & 3.58 & 14.2 & - & 4.19 & 9.5 & 0.0056 \\
\hline$Q_{3}(\mathrm{~mL} / \mathrm{min})$ & 0.308 & 26.4 & - & 0.0587 & 29.1 & - \\
\hline$V_{3}(\mathrm{~mL})$ & 158 & 22.1 & - & 13.6 & 27.6 & 0.0029 \\
\hline \multicolumn{7}{|c|}{ Residual variability } \\
\hline$\sigma 1$ & 0.0501 & $22.4(\mathrm{CV} \%)$ & & 0.0686 & $26.2(\mathrm{CV} \%)$ & \\
\hline$\sigma 2$ & 0.0029 & $0.0541(\mathrm{SD})$ & & 0.0038 & $0.0619(\mathrm{SD})$ & \\
\hline
\end{tabular}

The denotations are RSE (\%): relative standard error; $\sigma$ : residual variability; $V_{1}$ : central volume of distribution; $V_{2}, V_{3}$ : two peripheral volumes of distribution; $Q_{2}, Q_{3}$ : intercompartmental clearances.

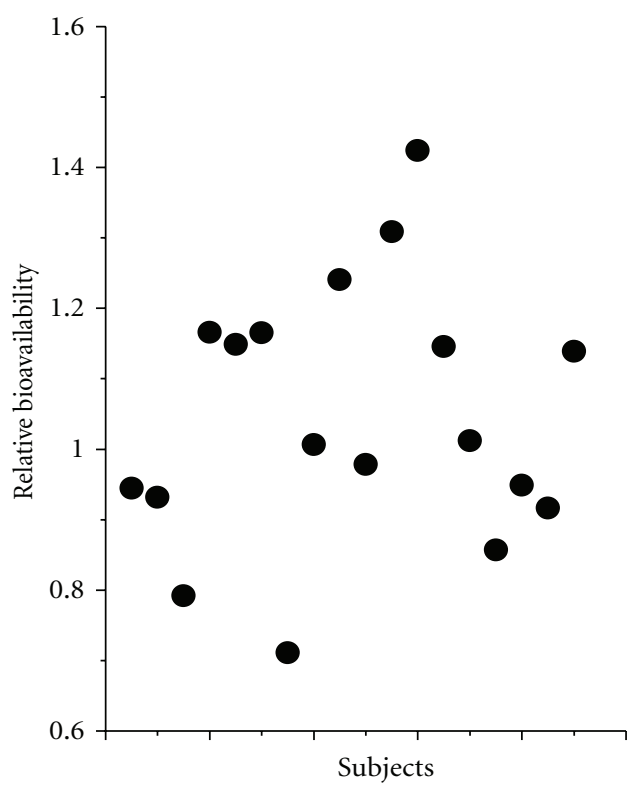

FIGURE 2: Relative bioavailability of each subject for male and female dogs. The values were derived from the ratio of dosenormalized AUC $\left(\mathrm{AUC}_{0-\infty} /\right.$ dose $)$ as listed in Figure 2. Each dot represents an individual subject. ${ }^{*} P<0.05$, there was a significant difference between males and females.

lysine and cefuroxime sodium was assessed by calculating $90 \%$ confidence intervals of the geometric mean ratios for $C_{\max }, \mathrm{AUC}_{0-t}$, and $\mathrm{AUC}_{0-\infty}$, which should between $80 \%$ to $125 \%$ [14]. Values for $T_{\max }$ were compared using nonparametric Wilcoxon two-sample test. Comparisons of the pharmacokinetic parameters between different gender levels were evaluated by paired $t$-test. Descriptive statistics were expressed as arithmetic means \pm standard deviation (SD) values. A $P$ value of less than 0.05 was considered statistically significant [15].

\section{Results}

3.1. Subject Characteristics. Each dog was individually weighted at 1 week and 2 week, and the demographic characteristics of the subjects were listed in Table 1. Insignificant difference $(P>0.05)$ was found in the age and weight for different dosages and genders of those dogs.

3.2. Noncompartmental Model Results and Statistical Analysis. The pharmacokinetic parameters of cefuroxime lysine, or cefuroxime sodium, were calculated by noncompartment model via WinNonlin and DAS: these results were listed in Tables 2 and 3. The one-way ANOVA test analyzed on the pharmacokinetic parameters obtained by WinNonlin and DAS softwares did not show any statistical difference between the two forms of cefuroxime. Cefuroxime lysine and cefuroxime sodium were rapidly absorbed and eliminated, having overall mean values of $t_{1 / 2}$ at approximately $1.15 \mathrm{~h}$ and $1.33 \mathrm{~h}$, respectively. The mean values of $C_{\max }$ and AUC for both antibiotics were significantly higher at the administrated doses of 40 and $80 \mathrm{mg} / \mathrm{kg}$, as compared with the $20 \mathrm{mg} / \mathrm{kg}$ dose $(n=6, P<0.01)$. There were no significant differences of the main pharmacokinetic parameters (except for $C_{\max }, \mathrm{AUC}_{0-t}, \mathrm{AUC}_{0-\infty}$ ) between the three administrated drug dosages. The mean $C_{\max }$ and AUC were increased in proportional to an increased drug dosage. In contrast, the other pharmacokinetic parameters seemed to be exhibited a dose-independent manner. After normalizing the values of $C_{\max }$ and AUC by the administrated dose, there was no significant difference for either 20 , or 40 , or $80 \mathrm{mg} / \mathrm{kg}$ of drug intake. From $C_{\max }$ and AUC of different doses, as listed in Tables 2 and 3, the pharmacokinetic parameters of both antibiotics agreed well with the linear dynamic features, in a range of $20-80 \mathrm{mg} / \mathrm{kg}$ of administration, with the correlation coefficient $\left(r^{2}\right)$ of at least over 0.77 (Figures $1(\mathrm{a})$ and $1(\mathrm{~b})$ ).

In order to investigate the relative bioavailability and bioequivalence of cefuroxime lysine and cefuroxime sodium, the ratio of dose-normalized AUC $\left(\mathrm{AUC}_{0-\infty} /\right.$ dose) between the two antibiotics was considered as the relative bioavailability. The average $\mathrm{AUC}_{0-\infty} /$ dose for cefuroxime lysine and 


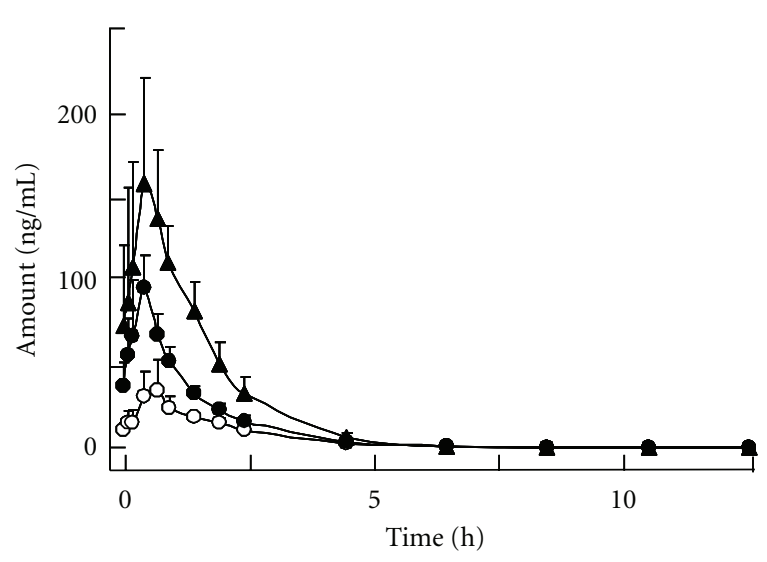

(a)

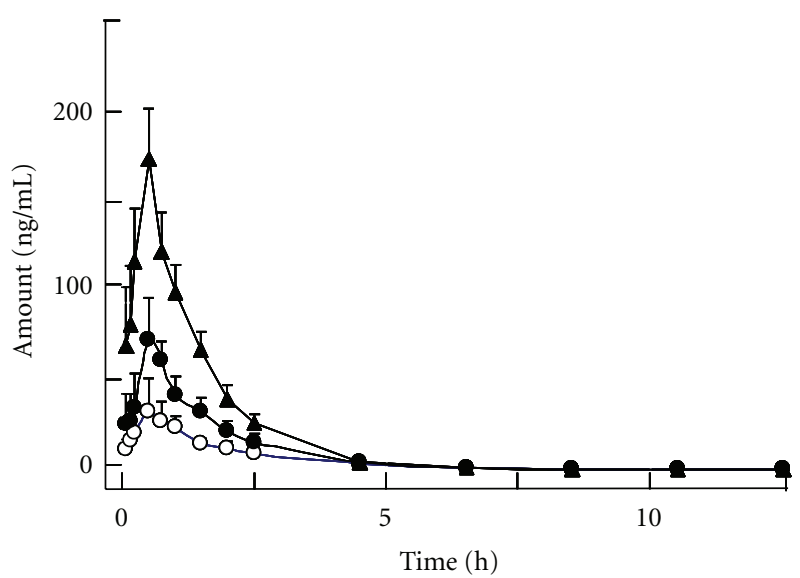

$20 \mathrm{mg} / \mathrm{kg}$

$40 \mathrm{mg} / \mathrm{kg}$

А $80 \mathrm{mg} / \mathrm{kg}$

FIGURE 3: The curves of mean plasma concentrations versus time for cefuroxime lysine (a) and cefuroxime sodium (b) were calibrated following $30 \mathrm{~min}$ of infusion The administrated drug concentrations were indicated. The plasma was obtained in different time periods. $10 \mu \mathrm{L}$ aliquot was injected into the UPLC-MS/MS system for analysis. The values are in mean \pm SD mg/L of plasma, where $n=6$.

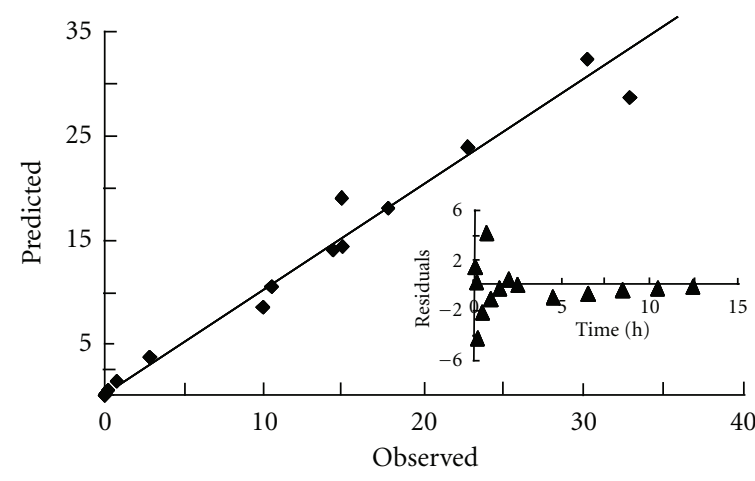

(a)

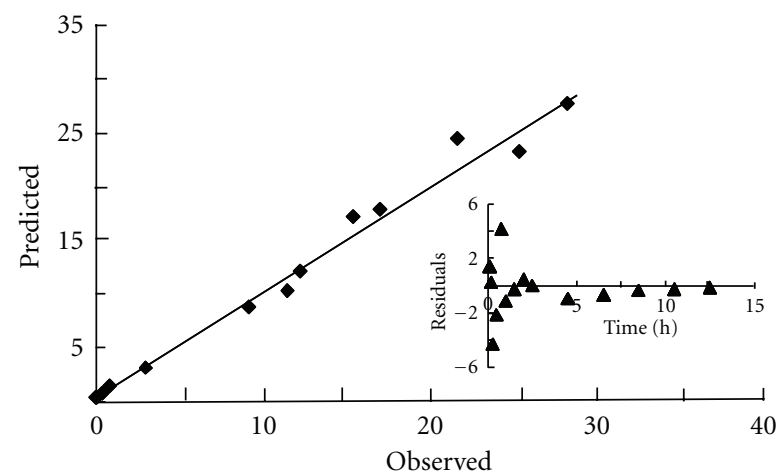

(b)

FIGURE 4: A 3-compartment open model of predicted versus observed drug concentration in the plasma of cefuroxime lysine (a) or cefuroxime sodium (b) under $20 \mathrm{mg} / \mathrm{kg}$ of drug administration. The insert showed that the plot of residuals (observed value - predicted) differs at different time points.

cefuroxime sodium was $3.28 \pm 0.18,3.27 \pm 0.46,3.24 \pm$ $0.71 \mathrm{~h} / \mathrm{L}$ and $3.27 \pm 0.58,3.04 \pm 0.59,3.21 \pm 0.42 \mathrm{~h} / \mathrm{L}$ at three different dosages, that are, 20,40 , and $80 \mathrm{mg} / \mathrm{kg}$, respectively (Tables 2 and 3 ). Thus, there were obviously no statistical differences between the pharmacokinetic parameters of the two antibiotics. In addition, the relative bioavailability $(n=$ 18 ) of cefuroxime lysine, between male and female, was 1.05 $\pm 0.18(0.71 \sim 1.42)$, with a significant difference $(P<0.05)$ between males and females (Figure 2).

By the two one-side $t$-test and the $T_{\max }$ by Wilcoxon test, the bioequivalence of the two antibiotics was determined on the basis of their $C_{\max }, \mathrm{AUC}_{0-t}$, and $\mathrm{AUC}_{0-\infty}$. At the $90 \%$ confidence intervals of the cefuroxime lysine versus cefuroxime sodium in the group of $20 \mathrm{mg} / \mathrm{kg}$, the calculated values were $90.2-112.1 \%$ for $C_{\max }, 96.0-103.0 \%$ for $\mathrm{AUC}_{0-t}$, and $96.0-103.0 \%$ for $\mathrm{AUC}_{0-\infty}$. The other two dose groups
( 40 and $80 \mathrm{mg} / \mathrm{kg}$ ) were both fit the bioequivalence criterion for $C_{\max }, \mathrm{AUC}_{0-t}$, and $\mathrm{AUC}_{0-\infty}$. In case of $T_{\max }$, the results showed that there was no significant difference between the two forms of antibiotics. Thus, cefuroxime lysine and cefuroxime sodium were having similar bioequivalence in terms of their rate and extent of absorption. In addition, there was no gender-based difference in the pharmacokinetic data of the two antibiotics (data not shown).

3.3. Population Pharmacokinetic Modelling. In a drug concentration-time curve, a nonlinear relationship between drug concentration in plasma and time was observed (Figure 3). The changes of drug concentration according to time were similar for both forms of the antibiotic, and the profiles were also similar under different dosages of the antibiotics. A 3-compartment open model was determined 

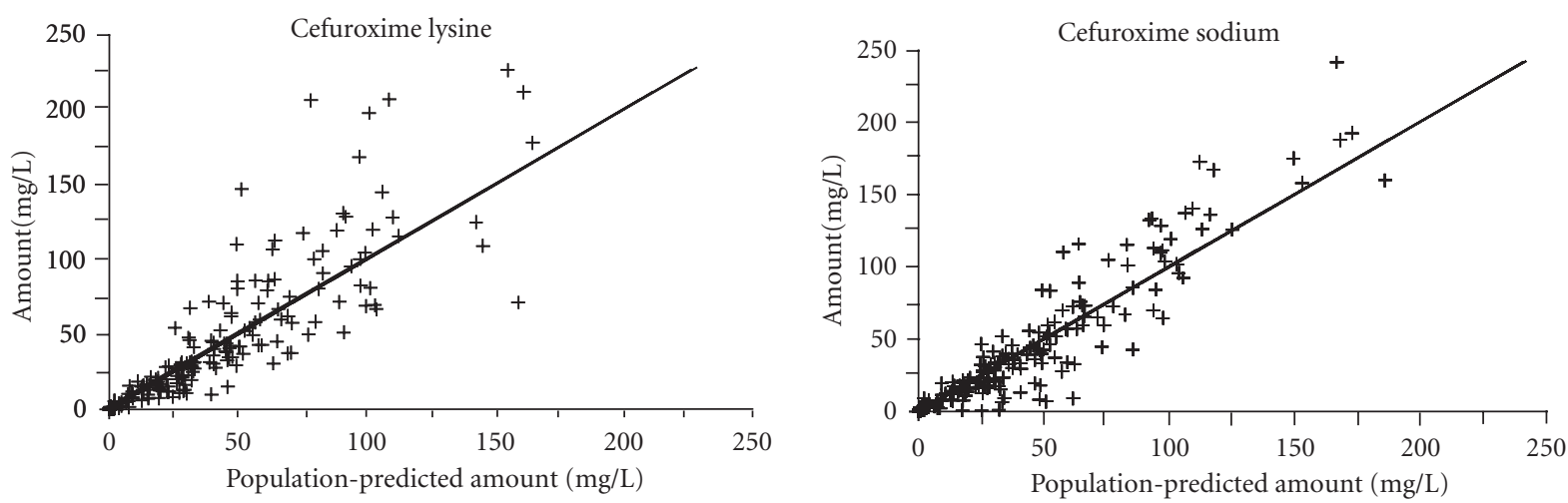

(a)
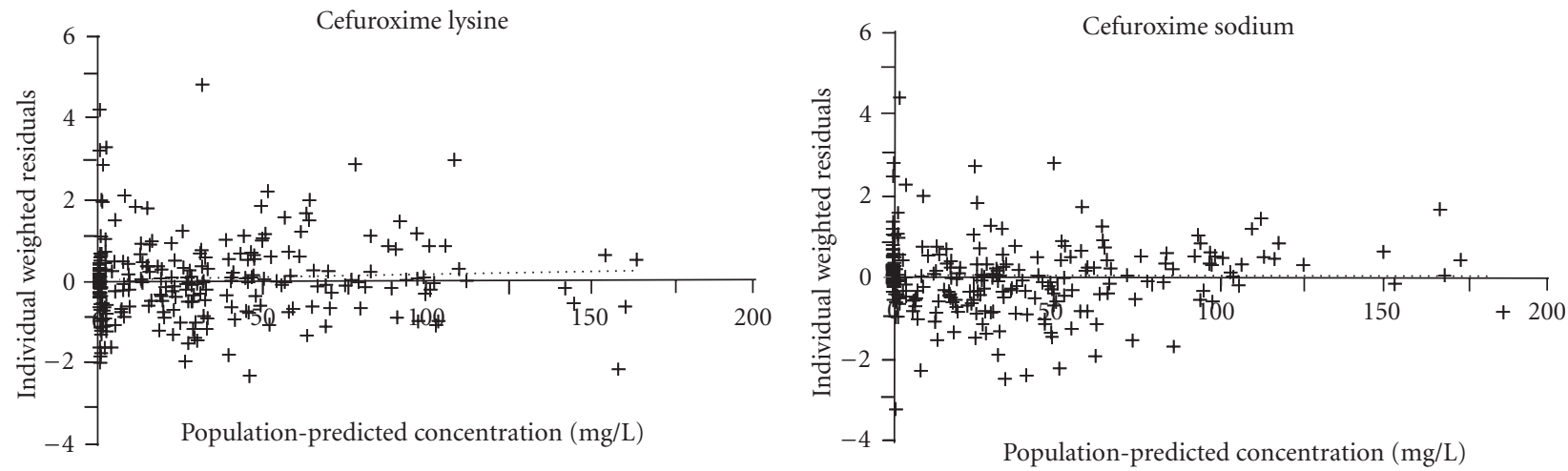

(b)
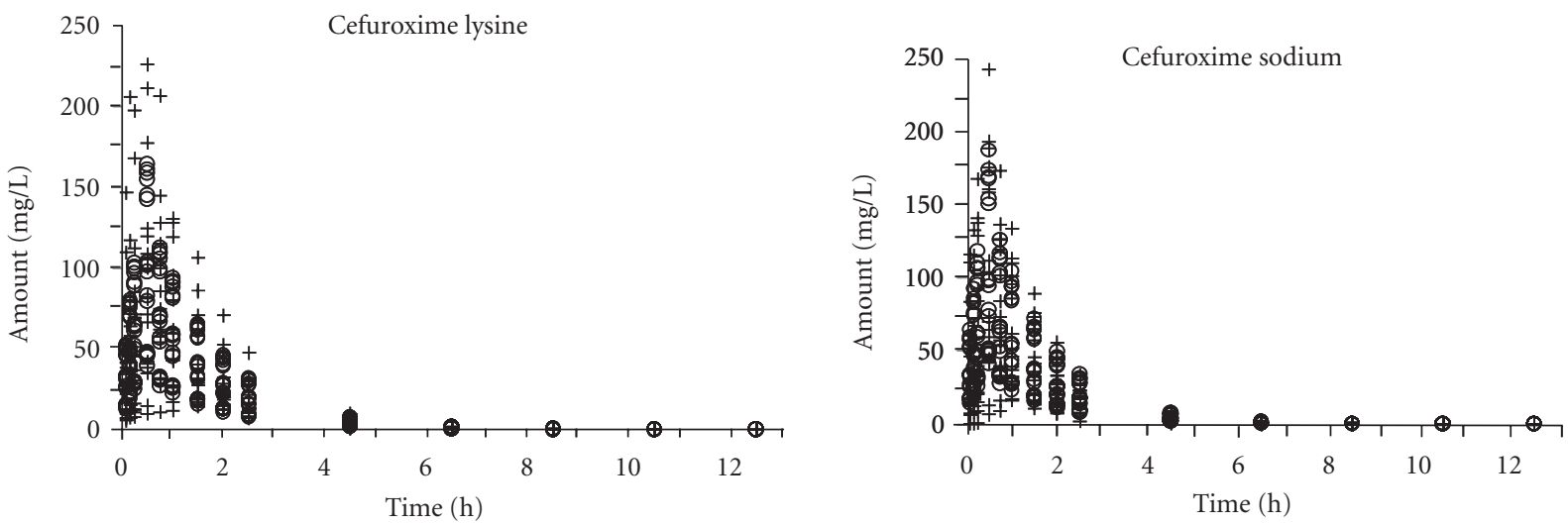

+ Experimental

+ Experimental

$\circ$ Predicted

○ Predicted

(c)

FIGURE 5: The population pharmacokinetic of cefuroxime lysine and cefuroxime sodium in dogs. (a): Experimental versus populationpredicted plasma concentrations was generated from the population pharmacokinetic. The values for calculation were from Figure 3. The line of identity was shown; (b): Individual Weighted Residuals (IWR) of the predicted concentrations versus the predicted concentration of the antibiotic in dog plasma; (c): a comparison of the pharmacokinetic properties of predicted and experimental drug concentrations in the plasma.

by an application of Akaike's Information Criterion (AIC) [16]. Figure 4 illustrates that the observed plasma concentrations, most of them, fall within the standard error bars from the predicted concentrations. The analysis indicated that the predicted versus the observed drug concentrations, as well as the residuals from the predicted pooled model
(Figure 4 insert), were exhibiting excellent agreement to the model. On the other hand, the correlation coefficient $\left(r^{2}\right)$ of the curve deriving from the predicted versus observed drug concentrations was greater than 0.96 , which indicated that the 3-compartment open model could therefore predict the population concentration of cefuroxime lysine, or 
cefuroxime sodium, when the dosages were given (Table 4). The results were in consistent with the model fitting by WinNonlin and DAS softwares.

In addition, the population pharmacokinetic parameters of cefuroxime lysine and cefuroxime sodium were estimated and listed in Table 5. Figure 5(a) showed that the dots were uniformly distributed around the line of identity, which indicated that the values of predicted drug concentration agree with the observed values very well. The individual weighted residual values (IWR, $-4 \sim 6$ ) for model-predicted concentration shown in the rectangular distribution were well acceptable (Figure 5(b)). In addition, a drug concentration time could be developed for both the predicted versus the measured concentrations of the antibiotic in plasma (Figure 5(c)), which indeed highly similar in both cases. This calculation therefore indicated that this population 3-compartment model was rather reliable to describe the final population pharmacokinetic parameters of cefuroxime lysine and cefuroxime sodium in dogs.

\section{Discussion}

The present study evaluated the linear pharmacokinetics, gender-related pharmacokinetic profiles and bioequivalence for $\beta$-lactam agent, cefuroxime lysine, and cefuroxime sodium, in beagle dogs for the first time. It was reported that the total body water was ranged from $0.556 \sim 0.660 \mathrm{~L} / \mathrm{kg}$ in healthy nonobese dogs, which were similar to the values of $V$ for both forms of the antibiotic [17]. This result suggested the distribution of the drug, most of them might be limited to the extracellular fluid compartment, and which were not extensively distributed to most of the organ tissues. However, a hypothesis was needed to be validated according to the tissue distribution of the antibiotics in future.

The pharmacokinetic properties of cefuroxime sodium have been extensively studied with the most appropriate pharmacokinetic model of a 2-compartment model [18]. Here, a 3-compartment model was selected in calculating the population pharmacokinetic, the possible reasons of that might be due to the difference in administration method (intravenous infusion) and/or the better accuracy in the chemical analysis.

In summary, this intravenous infusion demonstrated that the pharmacokinetic profiles of both antibiotics were similar. Further studies are required to determine the tissue distribution, as to provide a better understanding of its distribution and elimination in the body. The values of AUC were proportional to dose administrated, except the values of $\mathrm{CL}$ and $V$, and thus a linear pharmacokinetic was revealed here. There were not any side effects occurred during the trial, indicating that both forms of the antibiotic showed good tolerability. Moreover, no gender-based difference in the pharmacokinetic data was revealed, thus, the gender as a covariate was not included in the final model.

\section{Abbreviations}

$t_{1 / 2}$ : Terminal elimination half life

$C_{\max }$ : Maximum plasma concentration

$\begin{array}{ll}T_{\max }: & \text { Time to arrive at the } C_{\max } \\ V: & \text { The apparent volume of distribution at } \\ & \text { steady state } \\ V_{1}: & \text { Central volume of distribution } \\ V_{2}, V_{3}: & \text { Two peripheral volumes of distribution } \\ Q_{2}, Q_{3}: & \text { Inter-compartmental clearances } \\ \text { CL: } & \text { Total body systemic clearance } \\ \text { MRT: } & \text { Mean residence time } \\ \text { AUC }{ }_{0-t}: & \begin{array}{l}\text { Area under the curve to the last measured } \\ \text { point }\end{array} \\ \text { AUC }_{0-\infty}: & \begin{array}{l}\text { Area under the plasma concentration time } \\ \text { curve from } 0 \text { h to infinite time }\end{array} \\ C_{\text {adjusted }}: & C_{\text {max }} \text { normalized to dose } \\ \text { AUC }_{\text {adjusted }}: & \text { AUC } \\ \mathrm{CV}_{0-\infty} \text { normalized to dose } & \text { Coefficient of variation. }\end{array}$

\section{Acknowledgments}

The authors would like to thank Professor Karl Tsim of Hong Kong University of Science and Technology for his comment on this paper. This work was supported by the National Key Scientific Project for New Drug Discovery and Development (no. 2009ZX09301-012).

\section{References}

[1] A. Fiocchi, E. Calcinai, G. Beghi, and L. Terracciano, "Paediatric upper respiratory infections: the role of antibiotics," International Journal of Immunopathology and Pharmacology, vol. 23, no. 1, pp. 56-60, 2010.

[2] A. Barbour, S. Schmidt, W. R. Rout, K. Ben-David, O. Burkhardt, and H. Derendorf, "Soft tissue penetration of cefuroxime determined by clinical microdialysis in morbidly obese patients undergoing abdominal surgery," International Journal of Antimicrobial Agents, vol. 34, no. 3, pp. 231-235, 2009.

[3] J. C. Vazquez and E. Abalos, "Treatments for symptomatic urinary tract infections during pregnancy," Cochrane Database of Systematic Reviews, vol. 19, Article ID CD002256, 2011.

[4] G. M. Salzmann, F. D. Naal, F. von Knoch et al., "Effects of cefuroxime on human osteoblasts in vitro," Journal of Biomedical Materials Research A, vol. 82, no. 2, pp. 462-468, 2007.

[5] K. Abo El-Sooud, H. A. El-Banna, M. S. M. Hanafy, and A. Goudah, "Pharmacokinetics and intramuscular bioavailability of cefuroxime sodium in goats," Research in Veterinary Science, vol. 69 , no. 3, pp. 219-224, 2000.

[6] G. Benoni, L. Franco, A. Conforti, A. Totorizzo, and G. P. Velo, "Pharmacokinetics of cefuroxim and cefoxitin in experimental pleurisy in the rat," Giornale Italiano di Chemioterapia, vol. 28, no. 1-2, pp. 33-39, 1981.

[7] R. K. Chaudhary, A. K. Srivastava, and S. Rampal, "Modification of the pharmacokinetics and dosage of cefuroxime by endotoxin-induced fever in buffalo calves," Veterinary Research Communications, vol. 23, no. 6, pp. 361-368, 1999.

[8] C. A. Knoderer, S. A. Saft, S. G. Walker et al., "Cefuroxime pharmacokinetics in pediatric cardiovascular surgery patients undergoing cardiopulmonary bypass," Journal of Cardiothoracic and Vascular Anesthesia, vol. 25, no. 3, pp. 425-430, 2011. 
[9] M. Bischoff, A. Beck, P. Frei, and G. Bischoff, "Pharmacokinetics of cefuroxime in traumatic wound secretion and antibacterial activity under vacuum therapy," Journal of Chemotherapy, vol. 22, no. 2, pp. 92-97, 2010.

[10] L. S. Zhao, Y. L. Zhao, Q. Li et al., "A fast, sensitive, and high throughput method for the determination of cefuroxime lysine in dog plasma by UPLC-MS/MS," Talanta, vol. 89, pp. 84-90, 2012.

[11] J. W. Mandema, D. Verotta, and L. B. Sheiner, "Building population pharmacokinetic-pharmacodynamic models. I. Models for covariate effects," Journal of Pharmacokinetics and Biopharmaceutics, vol. 20, no. 5, pp. 511-528, 1992.

[12] S. L. Beal, A. J. Boeckman, and L. B. Sheiner, NONMEM: User's Guides, Universtiy of California at San Friacisco, San Francisco Calif, USA, 1988-1992.

[13] A. M. Nevill, S. Bate, and R. L. Holder, "Modeling physiological and anthropometric variables known to vary with body size and other confounding variables," American Journal of Physical Anthropology, vol. 41, pp. 141-153, 2005.

[14] P. Colucci, J. Turgeon, and M. P. Ducharme, "How critical is the duration of the sampling scheme for the determination of half-life, characterization of exposure and assessment of bioequivalence?" Journal of Pharmacy and Pharmaceutical Sciences, vol. 14, no. 2, pp. 217-226, 2011.

[15] J. Powers, "Statistical analysis of pharmacokinetics data," Journal of Veterinary Pharmacology and Therapeutics, vol. 13, pp. 113-120, 1990.

[16] K. Yamaoka, T. Nakagawa, and T. Uno, "Application of Akaike's information criterion (AIC) in the evaluation of linear pharmacokinetics equations," Journal of Pharmacokinetics and Biopharmaceutics, vol. 6, no. 2, pp. 165-175, 1978.

[17] S. Wamberg, N. C. F. Sandgaard, and P. Bie, "Simultaneous determination of total body water and plasma volume in conscious dogs by the indicator dilution principle," Journal of Nutrition, vol. 132, no. 6, pp. 1711s-1713s, 2002.

[18] P. Partani, S. Gurule, A. Khuroo, T. Monif, and S. Bhardwaj, "Liquid chromatography/electrospray tandem mass spectrometry method for the determination of cefuroxime in human plasma: application to a pharmacokinetic study," Journal of Chromatography B, vol. 878, no. 3-4, pp. 428-434, 2010. 

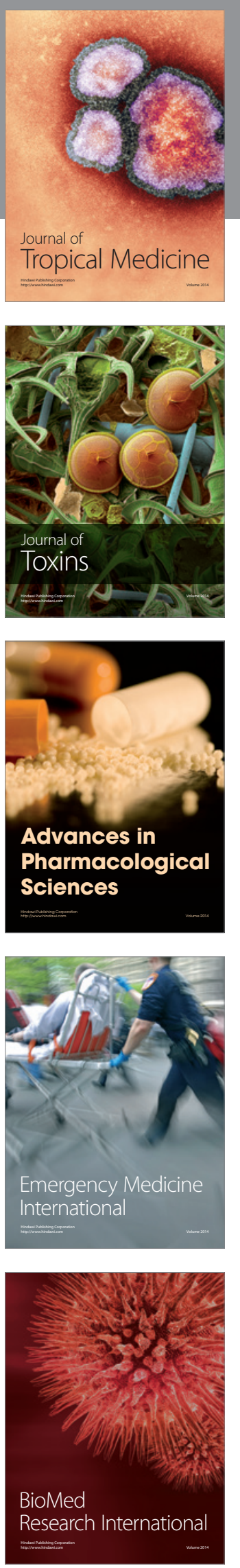
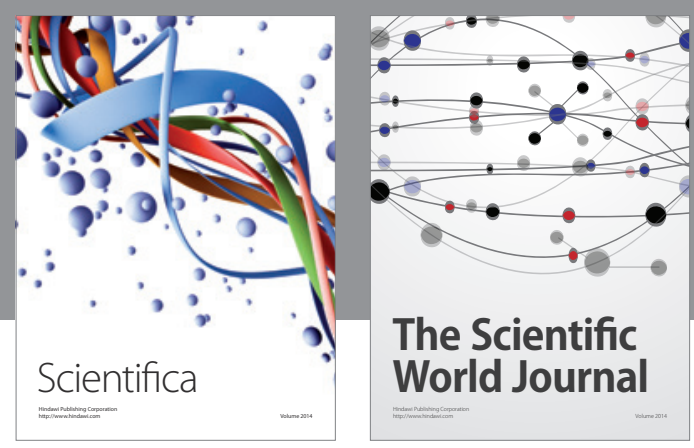

The Scientific World Journal
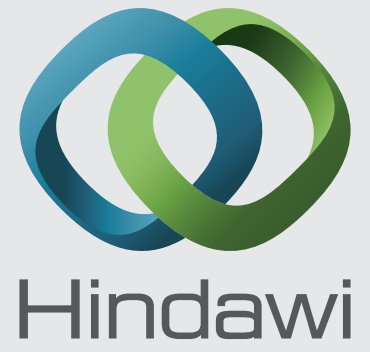

Submit your manuscripts at

http://www.hindawi.com
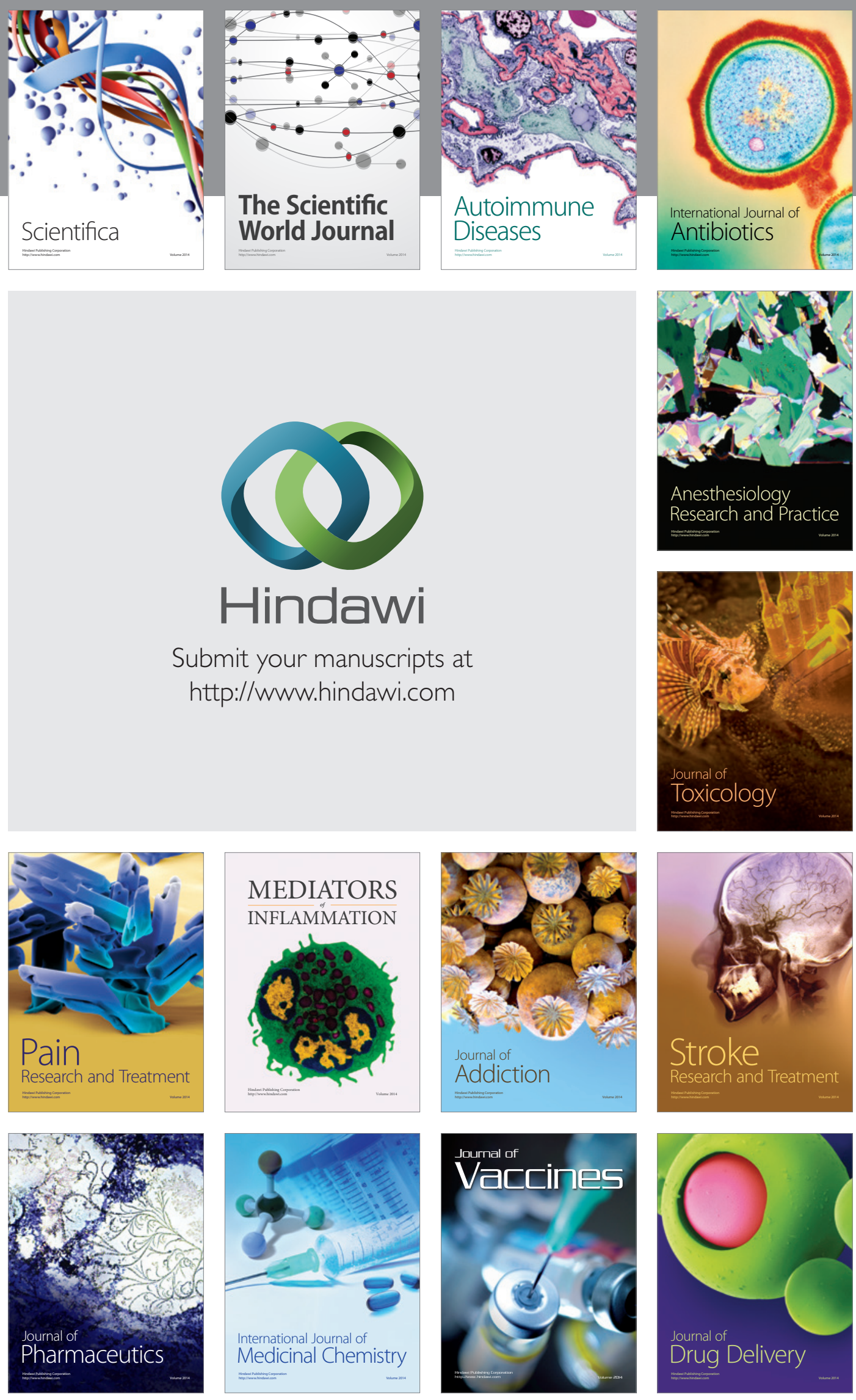